\title{
SOME PREMORBID CHARACTERISTICS RELATED TO BREAKDOWN IN CHILDREN WITH SCHIZOPHRENIC MOTHERS*
}

\author{
SARNOFF A. MEDNICK \\ Department of Psychology, University of Michigan, Ann Arbor, and \\ Psykologisk Institut, Department of Psychiatry, Kommunehospitalet, Copenhagen \\ and \\ Fini SCHULSINGER \\ Department of Psychiatry and Psykologisk Institut, Kommunehospitalet, Copenhagen
}

SCHIZOPHRENICS excite a good deal of behavioral research, the goal of much of this research is to produce information concerning the etiology of schizophrenia. It may be difficult, however, to isolate such etiological factors through studies carried out with individuals who have lived through the process of becoming and being schizophrenic. The behavior of these individuals may be markedly altered in response to correlates of the illness such as educational, economic and social failure, prehospital, hospital and post-hospital drug regimens, bachelorhood, long term institutionalization, chronic illness and sheer misery. In research with non-schizophrenics, these same factors have been shown to measurably affect behavioral research results. If researchers used control groups which were equated with their schizophrenic groups for all of these correlates of schizophrenia, then any observed differences could reasonably be ascribed to the variable of schizophrenia. But such control groups are apparently not readily available. Consequently, in comparisons of normals and schizophrenics, it is often difficult to judge what portion of the reported differences have unique relevance to schizophrenia. If, for example, comparisons of non-psychiatric prisoners and normals produced identical differences we might tend to attribute the schizophrenicnormal differences to the effects of institutionalization rather than some intrinsic quality of the schizophrenic.

In view of these considerations we decided to attempt to study the schizophrenic before he became ill. We turned to the study of young, high-risk populations (children with schizophrenic mothers). There are certain advantages in examining such subjects:

\footnotetext{
* This research has been supported by long-term support from the National Association for Mental Health, the Scottish Rite Committee for Research in Schizophrenia, and US PHS grant No. MH 06867. We would like to acknowledge the help of Ekspeditions-sekretaer Karlsen of the Folkeregister, Dr. M. Hauge of the Institute for Human Genetics, Drs. K. H. Fremming and A. Faurbye of Sct. Hans Hospital, Dr. O. Jacobsen of Statshospitalet, Nykøbing Sjaelland, Dr. J. B. Nielsen of Statshospitalet, Vordingborg, Drs. G. Magnussen, and K. Arentsen, Statshospitalet, Glostrup. Our co-workers have been: J. Vive Larsen, MI . Psychologists: Dr. D. Silber, Dr. J. Higgins, M. Kyng, B. Diderichsen. Social Workers: L. Maaløe, G. Skat Andersen, and U. Faltum. Research Assistants: B. Starr, L. Lehd, I. Beck, I. Petersen. Secretaries: K. Scharf, L. Monrad and K. Winther-Petersen.
} 
1. They have not yet experienced many aspects of the schizophrenic life such as hospitalization and drugs. Thus, these factors do not yet color their reactions.

2. The researchers, relatives, teachers and the subjcct himsclf do not know that he will become schizophrenic. This relieves the data of a certain part of the burden of bias. The bias is certainly not greater for the future schizophrenic than for other high-risk subjects who do not succumb.

3. The information we gather is current, not retrospective. That part of our inquiry which is retrospective is less so than it would be if the subjects were adults.

4. The data are uniformly and systematically obtained. This is in contrast to retrospective studies which make use of childhood and school records concerning adult schizophrenics.

5. One advantage of this method which may not be immediately apparent is the fact that the ideal controls for the high-risk subjects who become schizophrenic, are the high-risk subjects who develop other deviances and the high-risk subjects who do not become deviant. We consider it an advantage that such controls are an integral part of the design. (See Fig. 1.)

Example of Design of Study of High-Risk Samples

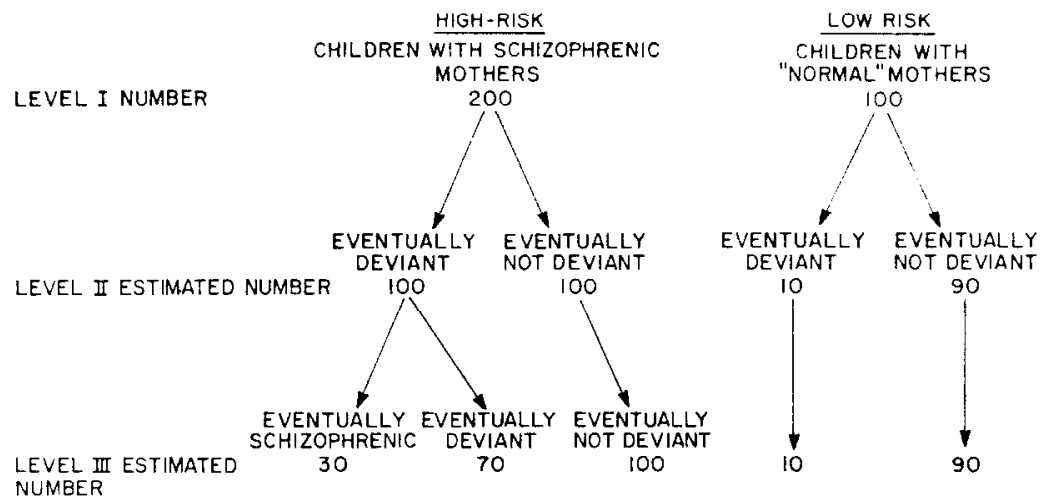

FIG. 1. This is an illustration of a study using high-risk samples of 200 children with schizophrenic mothers and 100 low-risk control subjects. The design can be conceptualized as developing at three levels. At the first level we can study the distinguishing characteristics of children with schizophrenic mothers in comparison with children with no familial psychiatric background. At the second level we can estimate that about $50 \%$ of the high-risk children will become seriously socially deviant. Rather good controls for these deviants are the children with schizophrenic mothers who do not become deviant. At the third level we can estimate that perhaps 30 of the 100 high-risk deviants will be diagnosed schizophrenic. The remaining 70 high-risk deviants may be considered appropriate controls for these 30 schizophrenics, as may the nondeviant, high-risk children and the low-risk children.

Such a study may not be readily or at least easily replicated. Others using even the same design may not be attracted to the same variables. In view of this fact a form of replication can be built into the design. At I evel II the 100 eventually deviant individuals may be conceived of as suffering breakdown in five waves of 20 subjects each. Thus, there are four potential replications of the first data analysis. (It should be mentioned that the precision of the replication might be attenuated if the waves differ in age of breakdown or diagnosis.) At Level III, the 30 schizophrenics may be conceived of as suffering breakdown in two waves of 15 subjects each. 
Our method involved the intensive examination of 207 "normally functioning" children who had chronic schizophrenic mothers and 104 control children. We estimate that the group of 207 children (high-risk group) contains more than 25 children who will some day be hospitalized for schizophrenia. We intend to follow these 311 children for 20 years from the inception date of the study, 1962.

The study had a number of aims:

Aim 1. An immediate aim was to compare the high-risk and low-risk subjects on a broad range of measures. Since about $50 \%$ of the high-risk group seems to be heading for some serious deviancy (Heston, 1966), differences between these two groups may relate to factors predisposing to deviance. Since the schizophrenics will represent a large subgroup of the deviants some of these differentiating characteristics may relate to schizophrenia.

Aim 2. We intend to follow both high- and low-risk samples and periodically retest them. Changes in personal characteristics and/or life conditions or their interactions which instigate or signal developing illness may make themselves evident through such procedures.

Aim 3. As mentioned above, $50 \%$ of the high-risk group may be expected to become seriously deviant. At some future time it will be possible to look back at our initial assessment and discover which (if any) of our test variables could have differentiated this deviant group from the high-risk subjects that develop more normally. Of the $50 \%$ of the high-risk group expected to become seriously deviant (approximately 100 individuals), about $30 \%$ may be expected to develop some form of schizophrenia. It will be of great interest to see which (if any) premorbid characteristics and life circumstances differentiate the schizophrenics from the other varieties of deviance, from the "non deviant" high-risk subjects, and from the low-risk controls. We will give special attention to the interaction of premorbid personal characteristics and life circumstances as possible factors contributing to mental illness.

The aims relating to premorbid differentiating characteristics assume that measures relating to factors predisposing to schizophrenia will be present in our test battery. The test battery was designed to be broad-ranging, tapping areas of function shown by empirical research to be aberrant in the schizophrenic. It is also related to a theory of schizophrenia (Mednick 1958, 1962) which will be referred to below in connection with the discussion of results. Despite our best efforts, the test battery represents a limited realm of variables. It is only too possible that the factors differentiating the preschizophrenic are not directly present in this limited realm. However, even if some of the variables are only indirectly related to variables crucial to the development of schizophrenia, our findings may serve to orient future efforts toward fruitful areas of study.

\section{METHOD OF PROCEDURE}

\section{Selection of site for the investigation}

The project was first attempted in the State of Michigan in the summer of 1961. It soon became clear that the necessary records in the State were inadequate for our purposes and that following the subject for 20 years would result in an unacceptable rate of loss of subjects (US Bureau of the Census, 1956; Lansing and Mueller, 1967). In contrast to this, a study by Fremming (1951) had $92 \%$ success in locating 5500 individuals in Denmark in 
60-year follow-up. When this work came to our attention it became clear that our study was possible in Denmark. Denmark also has the advantage of small size and great population concentration in the Copenhagen area.

The excellent follow-up record of the Fremming study is easier to understand in the context of the Danish Folkeregister. These municipal bureaus maintain a lifelong and up-todate register of the address of every resident of Denmark. Another Danish institution which proved to be of great value to this project is the National Psychiatric Register which maintains a central file on every psychiatric hospitalization in the Kingdom of Denmark. The use of these institutions will be described below.

\section{Reisby study}

Our first aim was to check, in Denmark, the frequency of schizophrenia among individuals with schizophrenic mothers. In view of recent apparent disparities between psychiatric genetics investigations in Scandinavia and other countries it is of special value now to have this independent check. In connection with this project, Reisby (1967) investigated the risk of hospitalization for schizophrenia for children of a relatively small, resident hospital, female schizophrenic, Danish population. This risk proved to be $10.4 \%$, which is in the lower range of other estimates, e.g. Kallmann (1946).

\section{SUBJECTS}

\section{Selection of schizophrenic mothers}

We chose to take children whose mothers are process schizophrenic for a number of reasons. (1) Allegations of paternity are not always free of challenge. It might be difficult to be quite sure of our major independent variable with alleged fathers, especially if they were schizophrenic. (2) Schizophrenic women have more children than schizophrenic men (Goldfarb, C. and Erlenmeyer-Kimling, L., 1961). In a study of all schizophrenic patients in a Danish state hospital we found schizophrenic women to be five times as fertile as schizophrenic men. (3) Psychodevelopmentally, mothers presumably play a greater role in shaping children. Using mothers has permitted us to carry out research on the effects of being reared by a schizophrenic mother (Higgins, 1966). (4) The offspring of process (typical schizophrenic mothers yield a higher rate of schizophrenia (Schulz, 1939, 1940; Lewis, 1957)).

\section{Diagnosis of mother}

Two experienced Danish psychiatrists trained together and then independently tested their reliability in making judgments from hospital records. Their agreement as to diagnosis on 20 test cases was found to be $100 \%$. They merely had to judge whether the mothers were typical schizophrenics. They were instructed to discard any questionable cases. Following this reliability check only one psychiatrist checked each record. For each mother a precoded form was filled out which listed her symptoms, provided information concerning her dates of hospitalization and made a summary of her clinical status. 
The intent in the selection of the mothers was to choose only cases that would be readily agreed upon in Europe or the United States as being severe and typical schizophrenics. We required at least 5 years of hospitalization, or at least three separate periods of hospitalization, each of at least 3 months' duration, with no sign of improvement during discharge, or an extended hospitalization plus a certified State Invalid Pension for schizophrenia. Excluded, were cases which did not have at least two different types of severe schizophrenic symptoms.

\section{Matching of high-risk and low-risk subjects}

Pairs of high-risk (H) subjects were matched on sex, age, father's occupation (the best measure of social class in Denmark; Svalastoga, 1959), rural-urban residence, years of education, and institutional upbringing vs. family life. Next, a single low-risk (L) subject was selected who was matched on these same variables individual for individual with each $\mathrm{H}$ pair.

In the case that an $H$ child was in a children's home, he would be paired with another $H$ child in a children's home. L children were also sampled from children's homes. In most of these L cases the parents had divorced, died, were alcoholics, suffered from serious somatic illnesses, or criminality. They afford the opportunity of some degree of control for the broken-home aspects of being a child of a schizophrenic mother.

Table 1 presents the mean values for the $\mathrm{H}$ and $\mathrm{L}$ groups for the matching variables used in this study. As may be seen, the average age of the sample was $15 \cdot 1$ years. There would have been some advantage in testing a younger group; however, it will take 20

Table 1. Characteristics of the Experimental and Control Samples

\begin{tabular}{l|c|c}
\hline & Control & Experimental \\
\hline Number of cases & 104 & 207 \\
Number of boys & 59 & 121 \\
Number of girls & 45 & 86 \\
Mean age* & $15 \cdot 1$ & $15 \cdot 1$ \\
Mean social class $\dagger$ & $2 \cdot 3$ & $2 \cdot 2$ \\
Mean years education & $7 \cdot 3$ & $7 \cdot 0$ \\
Per cent of group in children's homes & & \\
$\quad(5$ years or more) + & $14 \%$ & $16 \%$ \\
Mean number of years in children's & $8 \cdot 5$ & $9 \cdot 4$ \\
$\quad$ homes (5 years or more) + & $22 \%$ & $26 \%$ \\
Per cent of group with rural residence $\$$ &
\end{tabular}

* Defined as age to the nearest whole year.

$\dagger$ The scale runs from 0 (low) to 6 (high) and was adapted from Svalastoga (1959).

¥ We only considered experience in children's homes of 5 years or greater duration. Many of the Experimental children had been to children's homes for brief periods while their mothers were hospitalized. These experiences were seen as quite different from the experience of children who actually had to make a children's home their home until they could go out and earn their own living.

$\$$ A rural residence was defined as living in a town with a population of 2500 persons or fewer. 
years for the present sample to pass through a major part of the risk period for schizophrenia. The subjects' mean age was selected so as to maximise the probability that the investigators would still be alive at the conclusion of this risk period.

\section{Alarm network}

As the subjects of the long-term follow-up begin to breakdown, it will be crucial to be on the spot as soon as possible in order to gain a picture of the circumstances precipitating the breakdown. An alarm network was instituted to deal with this problem. First, through the health insurance system, each of the subjects has a family physician. These physicians are alerted to the fact that their patients are under study and provide information concerning contacts they may have with the subjects.

All hospitals on Zealand and all psychiatric hospitals in Denmark have submitted blank hospital registration cards to us. The 311 subjects have had these registration cards prepared for them using the particular forms of cards for each hospital. Also stamped on each card is a message requesting that the project be informed immediately if the subject presents himself for hospitalization. The secretaries responsible for informing us receive small financial incentives for every notification. The network has been operative for 2 years and seems effective.

\section{Testing procedure}

Until testing was complete none of the examiners was informed regarding whether the children tested were $\mathrm{H}$ or $\mathrm{L}$ subjects. All visits were scheduled by the social worker. The procedures were identical for all subjects.

Subjects arrived at 8 a.m.-height and weight were measured. They were then escorted to the psychophysiology laboratory where they underwent mild stress, conditioning and generalization procedures. They were then tested with a full Wechsler Intelligence Scale for Children (WISC) and the Minnesota Multiphasic Personality Inventory (MMPI). Then came lunch. After lunch they took two Word Association Tests (single word response and continual association) and completed an Adjective Check List describing themsclves. They then returned for a second psychophysiology session where they underwent mild stress, semantic conditioning and mediated generalization procedures. Finally, subjects were interviewed by a psychiatrist and given an honorarium.

\section{Psychophysiological procedures}

Psychophysiological measures relate to states of cortical activation and emotional arousal. Researchers in the area of schizophrenia have very frequently included these measures in their research designs. Psychophysiological techniques, particularly electrodermal measures, have revealed significant aberrancies in the schizophrenic (Venables, 1966). In addition, these measures are crucial to aspects of a theory of the etiology of schizophrenia proposed by the senior author (Mednick, 1962). Inclusion of these measures in a conditioning paradigm affords us the opportunity to record measures related to the learning and generalization of fear responses. We also wished to observe the psychophysiological response to mild stress. 
An Offner-Beckman Type R Dynograph was used to record the physiological variables. After washing and alcohol sponging at points of electrode placement, the subject reclined and was asked to relax. Respiration, heart rate, galvanic skin response (GSR) and electromyography (EMG) electrodes were attached.

Respiration. An Offner respiration transducer was fastened just above the waistline and below the diaphragm.

Heart rate. Electrodes were attached with rubber straps to the ankles and to the left arm just below the elbow.

$E M G$. Electrodes were fastened with elastic tape $2 \mathrm{~cm}$ above the eyebrows and $5 \mathrm{~cm}$ on either side of the nose line.

GSR. A special Wheatstone skin resistance bridge was constructed for the project (Ax and Zacharopolous, 1962). The bridge reversed the polarity of the 1.5 volt reference current every $1.2 \mathrm{sec}$. The input was processed from the bridge to the pre amplifier via a straight-through coupler. Recording was through high-sensitivity ink penwriters.

When the transducers were attached, recording was started and was continuous until the conclusion of generalization testing. $S$ was instructed to relax, and earphones were fitted.

\section{Conditioning, stress and generalization}

Approximately $30 \mathrm{sec}$ after the tape recorder was started, $S$ heard instructions informing him of the procedure, followed by 8 presentations of the CS (1000 cps tone). These 8 presentations were included to desensitize $S$ to the CS and provide information concerning $S$ 's orienting response. Nine seconds after the final "desensitization trial", conditioning trials began. UCS was an irritating noise of $96 \mathrm{db}$ presented for $4 \frac{1}{2} \mathrm{sec}$ following $\frac{1}{2} \mathrm{sec}$ after the onset of CS (54 db). There were 14 partial reinforcement trials ( 9 CS-UCS pairings, and 5 interspersed presentations of the CS alone). Trials were separated by intervals which varied from $17 \mathrm{sec}$ to $77 \mathrm{sec}$.

Following the final conditioning trial, there was an interval of $3 \mathrm{~min}$, following which conditioning and stimulus generalization testing began. Generalization stimuli were tones of 1311 cps $\left(G_{1}\right)$ and 1967 cps $\left(G_{2}\right)$. There were 9 trials, 3 each of CS, GS $S_{1}$, and $G_{2}$. Duration of $C S, G_{1}$, and $G_{2}$ was $2 \mathrm{sec}$, and stimuli were separated by intervals which varied from $10 \mathrm{sec}$ to $18 \mathrm{sec}$. The order of the CS, GS , and $\mathrm{GS}_{2}$ was counterbalanced.

The final conditioning and stimulus generalization-testing trial marked the end of the morning session, which took approximately $50 \mathrm{~min}$. $S$ was then disconnected from the apparatus and escorted from the laboratory.

The afternoon psychophysiology session was identical to the morning session except that verbal stimuli and verbal mediation were used for conditioning and generalization (Mednick and Wild, 1962). The verbal materials were taken from Kent-Rosanof word association norms we established on Danish schoolchildren between the ages of 9 and 16 years.

\section{Wechsler intelligence scale for children (WISC)}

There has been a considerable amount of research showing an IQ deficit in the childhood school record of adult schizophrenics (Albee and Iane, 1964; Lane and Albee, 1963; Lane and Albee, 1964). Despite limitations in methodology (Mednick and McNeil, in press), the 
great consistency of the findings prompted us to include the WISC. Added to this is the breadth of the perceptual, reasoning motor and memory functions, which may be examined in a standard manner. The tcst also yiclds examples of rcasoning and verbal behavior which may be analyzed by existent clinical techniques. A translation of the WISC commonly used in Denmark was administered in accordance with standard instructions.

\section{Minnesota multiphasic personality inventory ( $M M P I)$}

A test of personality characteristics was deemed essential. The size of the sample dictated the use of an objective measure. The MMPI has an extensive literature on the schizophrenic for purposes of comparison of results and thus seemed the obvious choice. The MMPI also offers the possibility of the establishment of premorbid scales for the schizophrenic and other deviant outcomes. One drawback of this Danish translation is the lack of corresponding Danish norms. However, Hathaway has pointed out that cross-cultural use of the Inventory has proven it to be quite "robust" in this respect (personal communication). The Inventory was shortened to 304 items by removing items deemed inappropriate or offensive to children. The items were printed on cards and individually administered in the standard manner. In cases where children had difficulty in reading, the examiner read the items aloud.

\section{Word association test (WAT)}

The involvement of thought disorder in schizophrenia and the use of associative techniques to isolate and observe these disturbances have been a frequent and fruitful approach to the study of schizophrenia. The Kent-Rosanof Word List was chosen because of the large body of comparison literature available. Danish word association norms did not exist so we gathered and tabulated the word associations of 145 Danish schoolchildren between the ages of 9 and 16. These norms enabled us to evaluate the statistical features of the sample's associations. It will be of great interest to observe changes in associative behavior correlated with changes in psychiatric status and other variables. The list was read to the subject with the instruction to respond to each word with the first single word that came to mind. Response latency was recorded.

\section{Continuous association test (CAT)}

In addition to the reasons cited above for inclusion of the WAT, we wished to study the flow of the subject's associations to a single word over a period of one minute. Research has indicated that differences between normals and schizophrenics change qualitatively and quantitativcly during the 1 -min period.

The 30 stimulus words were each printed on a card which was presented to the subject. He was asked to look at the word during the association period and report all of his associations to the word. Responses and latencies were recorded. If the subject gave multi-word responses or responded to his own associations rather than the stimulus he was cautioned two times. 


\section{Adjective check list $(A C L)$}

Whilc the interviewing psychiatrist and the WISC examiner wrote brief clinical sketches of the subjects it was clear that these would be difficult to handle statistically for 311 subjects. Nevertheless, we felt it to be of some importance to be able to summarize the clinical impression the subjects made on the professional personnel. The ACL was chosen because of its objective scoring and because of the large number of scales which have been empirically constructed using this test. The ACL also lends itself to the construction of new scales. The ACL also afforded an opportunity for the subject to describe himself in objective terms.

The ACL of 241 adjectives was handed to the subject with instructions to use it to describe himself. The interviewing psychiatrist, WISC and WAT administrators also used the ACL to describe each subject. Each simply checked all the adjectives that were applicable.

\section{Psychiatric interview}

An important reason for the inclusion of the psychiatric interview was to screen children that were already mentally ill. Four children were excluded from the sample on this basis. The interviewer focused on the subject's mental status, social history and attitudes. Parts of the interview were precoded; the interviewer also presented his clinical impression of the subject. The $30-40 \mathrm{~min}$ interview was conducted by the junior author in his office.

\section{Parental intervicw}

This interview was meant to give us information concerning the current social, familial and educational status of the subject. The interview also aimed at obtaining information relative to rearing conditions. A social worker interviewed the individual responsible for the child. The interview was highly structured with precoded sections. The interview usually took place in the home of the interviewee and had a duration of $1 \frac{1}{2}-2 \frac{1}{2} \mathrm{hr}$.

\section{School report}

Bower et al. (1960) and others have demonstrated the value of school information in delineating characteristics of the preschizophrenic. They obtained their information from teachers; this was our source of data. The teacher is a professional spending many hours with the children. He can make judgments concerning his interactions with them, their peer interactions and their academic achievement. A questionnaire was mailed to each subject's school with the request that the teacher that knows him best respond. Of 311 forms sent out, 310 were returned.

\section{Midwife's report}

Many investigators have suggested the possibility that schizophrenia may be a product of damage to the brain occurring during pregnancy or birth. Every birth in Denmark (except under extraordinary circumstances) is attended by a trained midwife who completes a detailed form concerning the pre- and post-birth condition of the mother, the birth process, and the condition of the new born. The forms were located and copied. 


\section{RESULTS}

The project is now in its fifth year. We shall present two data analyses that will serve to illustrate the manner in which this "follow-up high-risk" design may be exploited. (1) The first analysis compares the behavior and characteristics of the high- and low-risk groups. This comparison is relevant to Aim 1. Due to limitations of space, and in view of the fact that much of this material has appeared earlier (Mednick and Schulsinger, 1965a, 1965b; Mednick, 1966) this presentation will take the form of a narrative summary of some of the significant findings. (2) Twenty of the high-risk subjects have suffered psychiatric breakdown since the inception of the study. The second analysis reports on characteristics which differentiate these individuals from comparable high- and low-risk subjects. These results are relevant to Aim 3.

\section{High-risk vs. low-risk group comparisons}

Birth data. There is a general trend for the birth of the $\mathrm{H}$ subjects to have becn attended with more difficulties. This is in conformance with previous reports on pregnancy and delivery in schizophrenic women. Significantly more of the mothers of the $\mathrm{H}$ subjects tended to be unwed. The birth process took much longer for the $\mathrm{H}$ subjects and was perhaps therefore attended by significantly more exploratory examinations. Perhaps most significant is the fact that abnormal placentas were evidenced by $11.3 \%$ of the $\mathrm{H}$ subjects and only $1.2 \%$ of the L subjects. Many of the placental disturbances took the form of infarcts.

Psychophysiologic findings. Extremely consistent and highly significant differences were observed in the latency of the galvanic skin response (GSR). These differences, however, seem to be rather complex. Unequivocally and without exception, the $H$ group responds with a shorter period of latency to each of the nine stress stimuli. In every case the differences are significant and marked. This short latency period suggests that the $\mathrm{H}$ group is characterized by a volatile autonomic nervous system that is easily and quickly arouscd by mild stress.

The differences between the two groups in latency of response to more neutral stimuli are not as marked. Although the $\mathrm{H}$ group continues to respond more quickly, there are many instances in which this trend becomes reversed.

We predicted differences in amplitude of response, speed of recovery, and generalization responsiveness. The two predictions concerning amplitude of response and generalization were strongly supported. The $H$ group responds with much greater amplitude to the stress and to the generalization stimuli than does the I group.

In complete contradiction to our prediction is the fairly consistent finding that the $\mathrm{H}$ group recovered from its response to the stress stimuli at a relatively greater rate of speed. For the past 10 years our hypothesis in research in schizophrenia has been that the preschizophrenic should show slower recovery from stress. Our data seem definitely to contradict this hypothesis. We will discuss some interpretations of this finding below.

The $\mathrm{H}$ subject is an individual quick to react with extremely vigorous autonomic responses. His autonomic responses are not discriminating but overgeneralized. (Perhaps the overgeneralization is in part due to the excessively quick latency of the response system.) This very rapid, highly vigorous responding is balanced by an equally labile rate of recovery from autonomic imbalance. 
Cognitive findings. The single-word association and intelligence tests yielded few differences between the $\mathrm{H}$ and $\mathrm{L}$ groups. The $\mathrm{H}$ group tended to give more idiosyncratic and fragmented associations. While the $\mathrm{H}$ groups performed a bit more poorly on most of the subtests of the WISC, the differences only reached significance on the Arithmetic and Coding subtests.

In a thesis at the University of Copenhagen, Diderichsen (1967) compared the $\mathrm{H}$ and $\mathrm{L}$ group on the CAT. The $\mathrm{H}$ group gave a significantly greater number of responses; they also gave a greater percentage of clang associates, chain associations and repetitions of the response words. These findings suggest that disorders of association are already discernible in the thought processes of some members of the $\mathrm{H}$ group. Whether or not these are the individuals slated for schizophrenia remains to be seen. The low magnitude of the singleword association and intelligence test differences probably reflects the fact that no member of either group was mentally ill at the time of the first examination.

Level of adjustment. At the conclusion of the psychiatric interview, the psychiatrist rated the state of adjustment of each subject, taking into consideration personal and environmental factors. This resulted in a five-point scale: (1) poor, (2) relatively poor, (3) doubtful, (4) relatively good, (5) good. Twenty-four per cent of the $\mathrm{H}$ group was rated 1 or 2; only $1 \%$ of the L group fell into these categories.

Social-developmental factors. In the brief narrative summary which follows we will combine many individual findings.

The first characteristic that all of the $\mathrm{H}$ subjects have in common, of course, is that they have mothers who are schizophrenic. Their home life has not been harmonious, but has been marked by frequent parental quarrels. The mother has apparently been relatively dominant in the home. However, her influence has not been benign; the child sees her as scolding and unreliable and not worthy of his confidences.

This difficult environment has been imposed upon (or perhaps has been responsible for producing) a child whose autonomic nervous system is highly labile, reacting to threat abnormally quickly and with abnormal amplitude. To make things still more difficult, reactions are not specific, but overgeneralized. This serves to broaden the range of stimuli that are adequate to provoke this sensitive autonomic nervous system.

In school, the child's teachers recognize his tendency to get upset easily. He seems to react to excitement by withdrawing. He handles peer relations and classroom challenges by passivity. Perhaps this mode of reaction is learned, since it is usually followed by the reduction of his anticipatory fear. Despite the use of passivity and withdrawal, the child is still approachable and is performing relatively adequately. He shows his "nervousness" enough for his teacher to remark on it. However, having begun to learn avoidance behavior, it is difficult for the child to stop, since this takes him away from the very social situations in which he might learn more direct means of dealing with his anticipatory anxiety. His autonomic recovery being more rapid, his withdrawal is even more effectively rewarded. Since he withdraws, his peers reject him; and the circle gets tighter and more difficult to break.

Although, in general, the child performs adequately, he has already learned to effect momentary withdrawal responses whenever pressures build up. In tasks that require continuous concentration and effort (Arithmetic and Coding the the WISC), his performance will begin to slip. 
The child is a "loner" much of the time. He does not share associations with his peer group as much as does his schoolmate. In addition, he is beginning to learn to escape from autonomic arousal by drifting off into idiosyncratic thought.

Every statement in the preceding summary is based on a statistically significant finding separating the $\mathrm{H}$ and $\mathrm{L}$ groups. Two points should be made. First, the groups overlap on all of the measures mentioned. Second, the summary is written as though all of these characteristics were present in a single group of individuals. What is more likely is that different subgroups of the $\mathrm{H}$ group were responsible for the significant findings on different items.

\section{Twenty high-risk subjects who succumbed}

Since the 1962 assessment the Alarm Network and the follow-up interview have identified $20 \mathrm{H}$ risk subjects who have manifested severely abnormal behavior. We shall call these individuals the Sick Group. Of these, 12 have been admitted to psychiatric facilities or placed under psychiatric care. The remaining 8 are severe schizoids, delinquents, alcoholic or have manifested bizarre symptomatic behavior. Case summaries are presented in Table 2.

Why did these particular $\mathrm{H}$ subjects become ill? How are they different from the other $H$ subjects? The answers could lie in certain personal characteristics (physiological, psychological or early experiential) which they already possessed at the time of the 1962 assessment; the answers could lie with the experiences they have had since 1962; the answers could lie in the interaction of these factors. We have recently completed a personal examination and home interview of the $H$ and $L$ samples. Two aims of this personal examination were to oblain information on the course of the subject's recent life and observe the subject interacting with his family in his home. This information may help us to evaluate the role of recent experience in contributing to breakdown. These data are not yet available. In this report we limit ourselves to an attempt to fulfill Aim 3, to "discover which (if any) of our test variables could have differentiated this sick group from the high-risk group that developed more normally".

\section{Selection of comparison groups}

At an early stage of this research the $\mathbf{H}$ subjects were set off in matched pairs. It was hoped that these matched pairs would provide us with a preselected control for subjects who break down. This strategy failed for two reasons. First, while not ill enough to be in the Sick Group, many of the erstwhile controls are likely candidates and could hardly be said to have "developed more normally". In addition, the original matching variables did not include any indicant of the subject's psychiatric status at the time of the first examination (such as the interviewing psychiatrist's rating of Level of Adjustment). Many of the otherwise matched pairs were widely discrepant for Level of Adjustment. Any differences in the 1962 assessment data between such pairs of subjects might not be prognostic but might simply reflect already existing differences in Level of Adjustment.

In view of these two considerations we rematched each subject in the Sick Group, individual for individual, with one $\mathrm{H}$ subject and one $\mathrm{L}$ subject. The matching variables 
Table 2. Descriptions of Conditions of Sick Group

Male, born 16 March 1953; extremely withdrawn, no close contacts, 2 months' psychiatric admission following theft, currently in institution for boys with behavior difficulties, still performing petty thieveries.

Female, born 19 January 1943 ; married, one child, extremely withdrawn, nervous. Evidence of delusional thinking, pulls her hair out, has large bald area.

Female, born 29 March 1946; promiscuous, highly unstable in work, no close contacts, confused and unrealistic, psychiatric admission for diagnostic reasons, recent abortion, some evidence of thought disorder.

Male, born 1 July 1946; under minor provocation had semipsychotic breakdown in Army, expresses strange distortions of his body image, thought processes vague, immature.

Male, born 2 May 1944; severe difficulties in concentrating; cannot complete tasks; marked schizoid character; marginally adjusted.

Male, born 3 June 1947; lonely in the extreme; spends all spare time at home; manages at home only by virtue of extremely compulsive routines; no heterosexual activity; marked schizoid character.

Male, born 1 October 1953; no close contact with peers, attends class for retarded children, abuses younger children, recently took a little boy out in the forest, undressed him, urinated on hin and his clothes, and sent him home.

Male, born 17 January 1954; has history of convulsions, constantly takes antiseizure drug (Dilanthin), nervous, confabulating, unhappy, sees frightening "nightmares" during the day; afraid of going to sleep because of nightmares and fear that people are watching through the window, feels teacher punishes him unjustly.

Female, born 18 March 1944; nervous, quick mood changes; body image distortions, passive, resigned; psychiatric admission, paranoid tendencies revealed, vague train of thought.

Male, born 14 March 1952; arrested for involvement in theft of motorbike; extremely withdrawn, difficulties in concentration; passive, disinterested, father objected to his being institutionalized; consequently he is now out under psychiatric supervision.

Male, born 19 October 1947; level of intellectual performance in apprenticeship decreasing, private life extremely disorderly; abreacts through alcoholism.

Male, born 20 January 1944 ; severe schizoid character, no heterosexual activity; lives an immature, shy, anhedonic life, thought disturbances revealed in TAT.

Female, born 25 May 1947; psychiatric admission, abortion, hospital report suspects pseudoneurotic or early schizophrenia; association tests betray thought disturbance, tense, guarded, ambivalent. Current difficulties somewhat precipitated by sudden death of boy friend.

Male, born 13 August 1950; sensitive, negativistic, unrealistic; recently stopped working and was referred to a youth guidance clinic for evaluation. Is now under regular supervision of a psychologist.

Male, born 28 May 1947; history of car stealing, unstable, drifting, unemployed, sensitive, easily hurt, one year institutionalization in a reformatory for the worst delinquents in Denmark.

Female, born 1 June 1945 ; psychotic episode, one year of hospitalization; diagnoses from 2 hospitals: (1) schizophrenia, (2) manic psychosis.

Male, born 3 September 1946; severe schizoid character; psychotic breakdown in Army, preceded by arrest for car thievery. Now hospitalized.

Male, born 28 January 1953; perhaps border-line retarded; psychiatric admission for diagnostic reasons; spells of uncontrolled behavior.

Male, born 23 June 1948; repeatedly apprehended for stealing; severe mood swings, sensitive, restless, unrealistic; fired from job because of financial irregularities.

Female, born 5 July 1941 ; highly intelligent girl with mystical interests. Very much afficted by mother's schizophrenia. TAT reveals thought disorder. Receiving psychotherapy.

were: the psychiatrist's rating of Level of Adjustment at the time of the initial assessment, age, sex, and social class. In addition, we imposed the restriction that the $\mathrm{H}$ group controls must have either maintained or improved in their Level of Adjustment since the time of the first assessment. This rating was independently obtained by the junior author from the material of the personal follow-up mentioned above. Of the 20 controls from the H Group, 11 had shown definite improvement in Level of Adjustment; 9 had maintained their Level. These controls from the $\mathrm{H}$ Group will be called the Well Group. Comparable follow-up 
Level of Adjustment ratings are not yet available for the matched L Group control subjects.

The mean values for each of the matching variables may be found in Table 3. "Control Group" refers to the L comparison group. The socioeconomic status (SES) of these groups is somewhat lower than that of the parent $\mathrm{H}$ and $\mathrm{L}$ groups which had SES scores of 2.2 and $2 \cdot 3$, respectively. This is mainly due to the presence in the Sick Group of a disproportionate

\begin{tabular}{|c|c|c|c|}
\hline & Sick & Well & Control \\
\hline $\begin{array}{l}\text { Mean age } \\
\text { Mean socio-economic status } \\
\text { Mean level of adjustment } \\
\text { Number of females }\end{array}$ & $\begin{array}{l}15 \cdot 1 \\
1 \cdot 45 \\
3 \cdot 0 \\
5\end{array}$ & $\begin{array}{l}15 \cdot 1 \\
1 \cdot 05 \\
3 \cdot 0 \\
5\end{array}$ & $\begin{array}{l}15 \cdot 1 \\
1 \cdot 85 \\
3 \cdot 3 \\
5\end{array}$ \\
\hline Total N & 20 & 20 & 20 \\
\hline
\end{tabular}

Note: The figures in the table refer to the subjects' status at the time of the initial assessment. The social class seale was adapted from one developed for Denmark hy Svalastoga (1959). The scale runs from 0 (Low) to 6 (High). The Level of Adjustment rating is drawn from the Psychiatric Intervicw.

number of children raised in children's homes. (I'his factor was matched for both the Well and Control Groups.) SES is zero for such children. Notice also that the Control Group could not be perfectly matched with the Sick and Well Groups for Level of Adjustment because too few $\mathrm{L}$ subjects had low enough Level of Adjustment scores for this purpose. We have, however, selected the worst of the L Group for the Control Group.

This matching process yielded three groups. Two of these groups (Sick and Well) are drawn from the $\mathrm{H}$ sample, i.e. they have schizophrenic mothers. An experienced psychiatrist found these two groups to be equivalent in Level of Adjustment in 1962. Since that time the members of the Sick Group have suffered severe psychiatric breakdown; the members of the Well Group have tended to maintain or improve their level of adjustment. The matched Control Group, drawn from the L Group, is at the lower end of the "normal" psychiatric spectrum. We will now turn to a consideration of the variables in the 1962 assessment that differentiate these groups.

\section{Results}

The latest member of the Sick Group was brought to our attention only 3 weeks before this Conference. Consequently not all variables and tests have been analyzed. This is a preliminary report; more findings may be added in the future. The report of results will concentrate on differences between the Sick and Well Groups.

\section{Birth data}

The factors examined included mother's age, marital status, previous pregnancies, time for the birth process, explorations, irregularities, anaesthetic, prematurity, weight, length, and characteristics of the newborn. While there was a slight general tendency for the Sick 
Group to have had a more difficult birth, none of the differences reached statistical significance.

\section{Parent interview}

Of all the 88 coded items in the Parent Interview only a few significantly differentiated the groups. Most significant is the fact that the Sick Group tended to lose their mothers to a mental hospital quite early and permanently. These figures are shown in Table 4 . It is

\begin{tabular}{|c|c|c|c|c|c|}
\hline $\begin{array}{l}\text { Child's age } \\
\text { in years }\end{array}$ & Sick & Well & Control & $x^{2}$ & $p$ \\
\hline $0-1$ & 7 & 5 & 0 & & n.s. \\
\hline $1-2$ & 11 & 5 & 5 & & n.s. \\
\hline $3-5$ & 30 & 10 & 10 & & n.s. \\
\hline $5-10$ & 65 & 15 & 30 & $20 \cdot 6$ & $<0.01$ \\
\hline $11-13$ & 81 & 40 & 35 & $15 \cdot 1$ & $<0.01$ \\
\hline $14-17$ & 85 & 42 & 46 & $11 \cdot 8$ & $<0.05$ \\
\hline
\end{tabular}

Note: The Sick and Well Groups differ significantly for ages 5-10 $\left(\%^{2}=6.5,1 d f, p<0.01\right)$, for ages $11-13\left(\%^{2}=18 \cdot 63,1 d f, p<0 \cdot 01\right)$, and for ages $14-17\left(\chi^{2}=4.96,1 d f, p<0.05\right)$.

important to emphasize that the tabulated percentages refer to the total absence of the mother from the home during the specified period. Thus if the mother was in the home for 3 months during the third to fifth year of the child's life and absent thereafter, this absence was first coded in the 5-10 year category. It should be noted that the absence of the mother from the home occurred at about the same time and frequency for the Well and Control Groups. In every case where there is overall significance between the thrce groups the Sick and Well Group taken by themselves are also significantly different.

For the Sick and Well Groups, the absence of the mother from the home was in every case occasioned by psychiatric hospitalization. On the basis of length of hospitalization, degree of recovery between hospitalizations, and treatment received, the illness of the mother was rated as Very Scvere or Modcratcly Scvere. Of the Sick Group mothers, $75 \%$ wcre rated as Very Severe; $33 \%$ of the Well Group mothers were rated as Very Severe $\left(\chi^{2}=\right.$ $6 \cdot 35,1 d f, p<0 \cdot 05)$. The mothers who were Very Severely ill left the home for the hospital at a time when child was significantly younger.

In view of the greater severity of illness of the mothers who left the home early, these data concerning the mothers' absence from the home could be interpreted in relatively environmental or relatively genetic terms. It is also of interest that absence of the mother from the home was correlated with signs of disturbed behavior even in the initial assessment.

\section{School report}

The teacher found it characteristic of $67 \%$ of the Sick Group that when upset or excited their reaction persisted and they continued to be upset. He reported this for only $22 \%$ of the Control Group and $23 \%$ of the Well Group $\left(\chi^{2}=6 \cdot 69,2 d f, p<0 \cdot 01\right)$. 
The Sick Group was also rated by the teacher as being more disturbing to the class. We can identify subjects who were either rated as being class disciplinary problems, domineering, aggressive and creating conflicts, or disturbing the class with chatting. Fifty-three per cent of the Sick Group, $18 \%$ of the Well Group and $11 \%$ of the Control Group were listed in one or more of these three categories. The frequencies for the three groups are significantly different as are the Sick-Well differences taken by themselves.

\section{WISC and WAT}

There were no statistically significant differences on these tests between the Sick and Well Groups. On all 12 of the WISC subtests the Well Group achieved a higher mean raw score than did the Sick Group. The three groups differed significantly on the Picture Arrangement Subtest; however, the Sick Well Group differences were not significant.

\section{Continual association test}

In this test where the subject is asked to give multiple single-word associations to a stimulus word, the Sick Group distinguished itself by frequently rattling off a whole series of words which were interrelated but contextually relatively irrelevant. (Opremsning in Danish). This series might be given to the stimulus word "Afraid" as follows: "Mother is afraid; father is afraid; brother, sister, aunt, uncle, ete." The mean Opremsning scores (corrected for Total Number of Response) for the Sick, Well and Control Groups were 1.33, $0 \cdot 11,0 \cdot 33$, respectively $(\mathrm{F}-4 \cdot 33,2 / 51 d f, p<0 \cdot 05)$. The Sick $v . s$. Well Group differences were also significant $(t-2 \cdot 30,36 d f, p \cdot 0 \cdot 05)$.

Another characteristic of the associations of the Sick Group is a tendency to slide away from the original stimulus word, despite cautions by the examiner. This characteristic has been named "Drifting"; each of the Sick and Well Groups' sets of associations to each of the 30 stimulus words has been rated on a scale from 1 (no drifting) to 3 (much drifting). The Sick Group had a mean Drifting score of $1 \cdot 72$, the Well Group $1 \cdot 33(t-2 \cdot 10,38 d f$, $p<0 \cdot 05)$.

\section{Electrodermal measures}

Basal level

There were no significant differences among the three groups in basal level at any point. The basal levels all hovered around the mean $H$ Group levels. The relatively low basal skin resistance of the Control Group is probably related to their relatively low Level of Adjustment rating.

\section{Responsiveness-stress stimuli}

Table 5 presents the mean GSR amplitude for the three groups for the stress stimuli. As can be seen, the Sick Group gives the largest responses to the stress stimuli with the Well Group falling in the middle. On 3 of the 9 trials differences between the Sick and Well Groups were significant. On most of the stress trials the variance for the Sick Group proved to be 5-7 times that of the Well Group. This suggests that a subgroup of the Sick Group 
Table 5. Mean Amplitude of GSR Response to Stress Stimuli, Conditioned Stimuli and Generalization Stimuli (Comparison of Sick, Well and Control Groups)

\begin{tabular}{|c|c|c|c|c|}
\hline \multirow{2}{*}{$\begin{array}{l}\text { Points of } \\
\text { measurement }\end{array}$} & \multicolumn{4}{|c|}{ Mean GSR response in ohms } \\
\hline & Sick & Well & Control & $p^{*}$ \\
\hline \multicolumn{5}{|l|}{ UCS Trials } \\
\hline CS-UCS I & 25,859 & 17,194 & 9,238 & $<0.01 \dagger$ \\
\hline CS-UCS II & 14,467 & 10,472 & 6,583 & $<0.05$ \\
\hline CS-UCS III & 11,128 & 8,167 & 4,133 & $<0.01$ \\
\hline CS-UCS IV & 10,823 & 11,567 & 5,365 & n.s. \\
\hline CS-UCS V & 10,759 & 6,859 & 4,900 & $\times 0.05$ \\
\hline CS-ICS VI & 10,900 & 5,494 & 3,606 & $<0.05 \dagger$ \\
\hline CS-UCS VII & 8,778 & 6,728 & 2,922 & n.s. \\
\hline CS-UCS VIII & 10,983 & 5,761 & 4,241 & $<0.05 \dagger$ \\
\hline CS-UCS IX & 9,682 & 7,217 & 3,244 & $<0.05$ \\
\hline \multicolumn{5}{|l|}{ CS Trials } \\
\hline CS 1 & 3,744 & 2,917 & 3,189 & n.s. \\
\hline $\mathrm{CS} 2$ & 5,394 & 1,959 & 4,094 & n.s. $†$ \\
\hline CS 3 & 6,139 & 1,617 & 2,853 & n.s. $\dagger$ \\
\hline CS 4 & 5,694 & 2,067 & 1,433 & n.s. \\
\hline CS 5 & 6,178 & 3,106 & 1,711 & n.s. \\
\hline \multicolumn{5}{|l|}{ Generalization Trials } \\
\hline CS (1) & 6,611 & 2,717 & 1,300 & $<0.05$ \\
\hline GS I (1) & 6,189 & 2,822 & 422 & $<0.05 \dagger$ \\
\hline GS $11(1)$ & 3,739 & 1,422 & 233 & $<0.05$ \\
\hline GS (2) & 5,222 & 2,389 & 756 & $<0.05$ \\
\hline GS I (2) & 4,400 & 2,139 & 50 & n.s. \\
\hline GS II (2) & 2,088 & 1,278 & 0 & $<0.05$ \\
\hline
\end{tabular}

* Significance of differences was tested in all cases by analysis of covariance. Basal level just preceding response was the covariance control.

$\uparrow$ Significant $t$ test between Sick and Well.

might have given abnormally large responses which were producing the mean differences in response amplitude. This point will be discussed below. A count was made of the number of individuals responding to the stress stimuli. As almost everyone responded on almost every trial, there were no differences between the groups on this measure.

A comparison of the Sick and Well Groups with the total $H$ Group reveals that on most trials these two groups fall on either side of the total $\mathrm{H}$ Group. However, reversals occur and the differences are not large.

\section{Responsiveness-conditioned stimuli}

There seems to be some evidence that the Sick Group showed more conditioning than the other groups. This may be seen in Fig. 2. The Well and Control Groups show almost no evidence of conditioning. The mean summated GSRs to the conditioned stimuli for the Sick and Well Groups were 5430 and $2311 \mathrm{ohms}$ respectively. This difference was significant 
$(t=2 \cdot 15,38 d f, p<0 \cdot 05)$. As may be seen in Table 5 , the Sick and Well Groups differed significantly on the second and third conditioning trials.

A count was made of the number of CRs per subject. This conditioning score could vary from 0 to 5. The Sick, Well and Control Groups had means of 3.28, 2.00 and 1.28 respectively. These three means were significantly different $(F=4.72,2533 d f, p<0.05)$ as were the Sick and Well means $(t=2 \cdot 00,38 d f, p<0 \cdot 05)$.

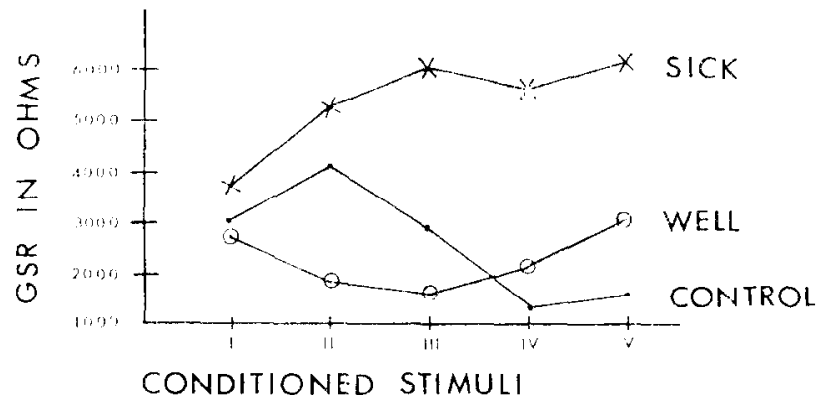

Fiki. 2. Amplitude of conditioned responses for 5 test trials with CS alone (for Sick, Well and Control Groups).

Demonstrating a conditioned response with the GSR as a response measure has always proven difficult because of the relatively rapid adaptation of the GSR. This suggests that rapid adaptation could have been a reason for the poor conditioning shown by the Well and Control Groups (see Fig. 2). On the other hand, it could be taken as an indication that the Sick Group is not so much evidencing conditioning as failing to habituate. This argument can be countered by pointing to the fact that from Trials 1 to 5 the CRs of the Sick Group tended to increase in amplitude (unfortunately this increase was not significant). This increase was taking place while their responses to the UCS (among which the CS trials are mixed) were decreasing.

The weight of the evidence slightly favors the conclusion that the Sick Group evidenced superior GSR conditioning. When the conditioning performance of the Sick and Well Groups is compared with that of the total $\mathrm{H}$ Group this conclusion is strengthened. The Well Group behaves like a somewhat enfeebled version of the total H Group.

\section{Generalization}

The $C S$ and $G_{1}$ and $\mathrm{GS}_{2}$ were presented in extinction test procedures 3 times each in counterbalanced order at the conclusion of conditioning. Table 5 and Fig. 3 present the mean amplitude of the generalization responses for the first 2 test trials. The third test trial data are not presented since very few subjects were responding.

The generalization responsiveness of the Sick Group is well above the level of the Well and Control Groups; the differences are significant on 5 of the 6 trials. When each subject is given a generalization score by adding together the amplitude of his responses to the first presentations of $\mathrm{GS}_{1}$ and $\mathrm{GS}_{2}$, the Sick Group evidences significantly more generalization than the Well Group $(\mathrm{U}=222, \mathrm{Ns}=18,18, p<0.04)$. As can be seen in Fig. 3, the Well 
Group level of generalization responsiveness is about the same as that of the total H Group. The Sick Group is well up above this level.

It should also be pointed out that the shape of the gradients are approximately the same for the Sick, Well and total $\mathrm{H}$ Groups (concave downward) while the gradients for the Control and total $L$ Groups are in the normal concave-upwards form (Mednick and Freedman, 1960). This is also shown in the fact that the amount of relative generalization (ratio of generalization responsiveness to conditioned responsiveness) is about the same

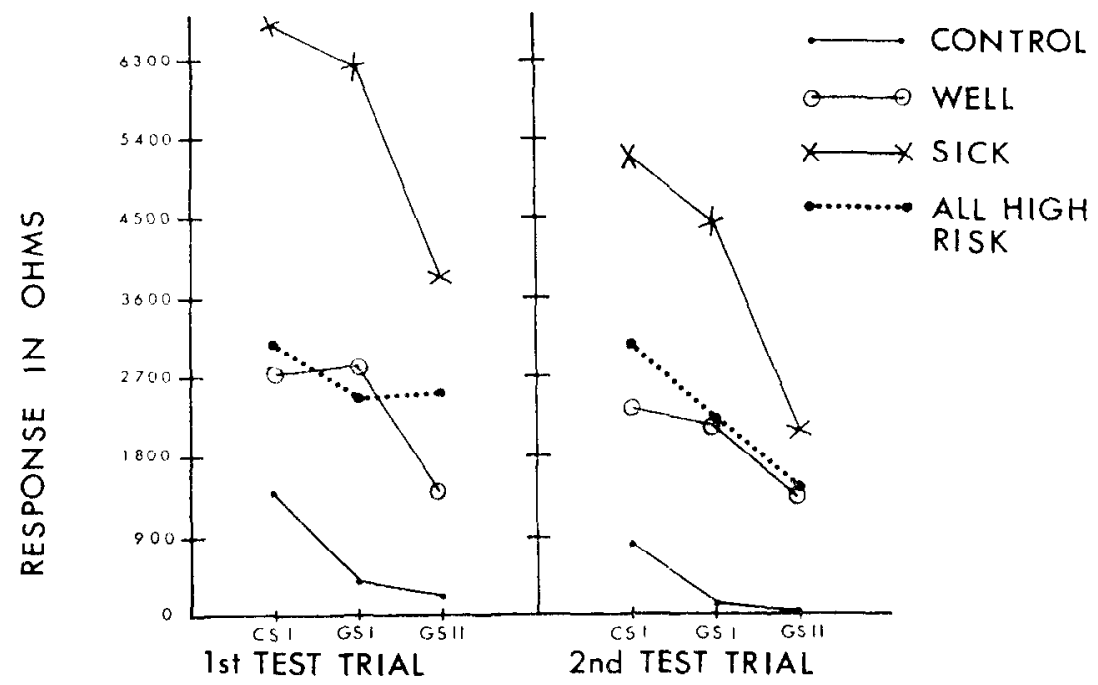

Fig. 3. Generalization gradients for Sick, Well, Control and entire H Groups.

for the Sick and Well Groups. Another way of saying this is that the Sick and Well Group generalization curves are essentially parallel and different from the Control curve. The earlier comparison of the $\mathrm{H}-\mathrm{L}$ gradients demanded the interpretation of an essential difference between these groups in generalization responsiveness. Both the Sick and the Well Groups continue to evidence this heightened generalization responsiveness. The fact that the Sick and Well Groups evidence parallel curves could suggest that some additional factor might be acting to increase the overall responsiveness of the Sick Group. This factor could either be a higher level of arousal or a failure of habituation or both.

\section{Latency}

A summary of the latency data may be found in Fig. 4. The groups differed significantly on all but one of the trials with the UCS (stress stimuli). The mean latencies across all UCS trials were $1.57,1.77$ and $2.47 \mathrm{sec}$ for the Sick, Well and Control Groups respectively $(\mathrm{F}=8.63,2 / 52 d f, p>0.005)$. Of great interest in Fig. 4 is the difference in habituation shown on the one hand by the Control and Well Groups and on the other by the Sick Group.

This difference is especially marked in response to the stress stimuli. The Control and Well Groups' rapid habituation may be seen in the progressive increase in their response 
latencies from the first to the last of the stress trials. The latencies of the Sick Group prcgressively decrease suggesting a negative habituation or even increasing irritability. The Sick Group distinguishes itself quite sharply from the Well Group in this regard. Moving from UCS Trials I-IX, $69 \%$ of the Well Group exhibits a slowing of response latency; $75 \%$ of the Sick Groups actually increase the speed of their response. This difference is significant $\left(\chi^{2}=6 \cdot 13,1 d f, p<0 \cdot 02\right)$. A tendency for the same failure of habituation of latency in the Sick Group is also shown in response to the conditioned stimuli (Fig. 4).

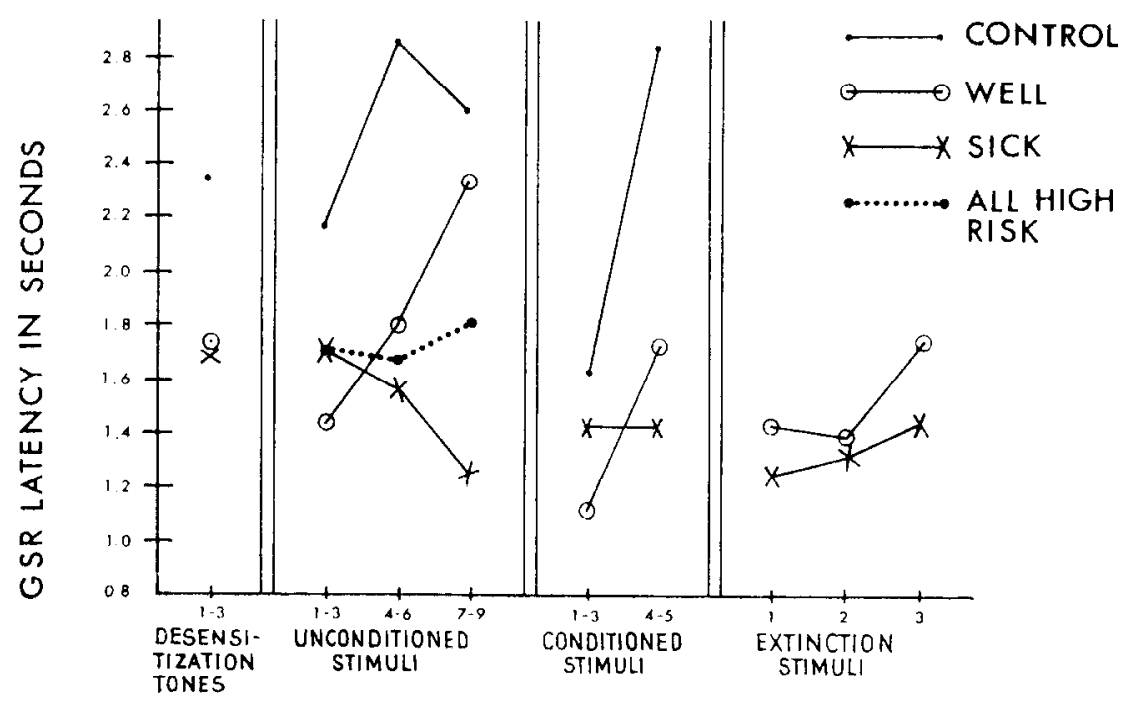

FIG. 4. Mean GSR latencies for the 3 groups for the entire session. Note that the Control Group latencies are omitted for the Extinction Stimuli Trials 1,2 and 3. These were omitted since there were very few responses and the latencies were completely off the figure. The mean latencies for the Control Group for Trials 1,2 and 3 were $2 \cdot 63,3 \cdot 12$ and $4 \cdot 83 \mathrm{sec}$ respectively.

As is also indicated in Fig. 4, the Sick and Well Groups were substantially quicker than the Control Group in latency of response. This mirrors the differences between the parent $H$ and $L$ Groups.

\section{Recovery:}

We devised a rather simple score to analyze the recovery results, the number of ohms recovered per second. We have used the time to half-recovery as the score for this index since this initial recovery phase is less likely to be contaminated by intruding external stimuli (such as the next stress stimulus) or internal stimuli. If a response were $1000 \mathrm{ohms}$ and the recovery of half of that response took $10 \mathrm{sec}$ then the subjects' recovery rate was 50 ohms per second.

We have not studied the operating characteristics nor GSR correlates of this measure and to our knowledge neither has anyone else. However, it is possible to guess that it is related to basal level.

Mean ohms recovered per second is reported in Table 6 for the Sick, Well and Control Groups. Because of our interest in evaluating degree of distribution overlap with this mea- 
sure, the differences were evaluated by the Mann-Whitney U-test. Significance levels were determined by reference to a set of prepared tables (Auble, 1953). All comparisons of the Sick and Control Groups were significant. All comparisons of the Well and Control Groups

TABLE 6. RATE of ReCOVERy OF GSR ResPonse to Stress Stimul!

\begin{tabular}{l|ccc}
\hline \multirow{2}{*}{ UCS trial } & \multicolumn{3}{|c}{ Mean ohms recovered per sec. } \\
\cline { 2 - 4 } & $\begin{array}{c}\text { Sick } \\
\text { Group }\end{array}$ & $\begin{array}{c}\text { Well } \\
\text { Group }\end{array}$ & $\begin{array}{c}\text { Control } \\
\text { Group }\end{array}$ \\
\hline 2 & 1607 & 634 & 521 \\
3 & 1538 & 651 & 595 \\
4 & 1386 & 764 & 394 \\
5 & 1230 & 615 & 582 \\
6 & 1282 & 606 & 331 \\
7 & 1816 & 749 & 401 \\
8 & 1490 & 884 & 392 \\
9 & 1406 & 691 & 590 \\
\hline
\end{tabular}

Notes: (1) The rate of recovery is computed for the first half of the ohms recovered. If a response were $1000 \mathrm{ohms}$ and recovery of half of that response took $10 \mathrm{sec}$ then the recovery rate was $50 \mathrm{ohms} / \mathrm{sec}$.

(2) UCS Trial 1 was omitted since most subjects did not succeed in recovering half of their response to this stimulus before the onset of UCS 2.

were not significant. Comparisons of the Sick and Well Groups were significant for Trials $2,3,4,5,6$ and 9 . Trials 7 and 8 were not significantly different. The recovery rate of the Sick Group is substantially greater than that of the Well or Control Groups. The latter two tend to be relatively similar to one another.

The measure separates the groups better than any other in our test battery. The overlap between the Sick and Control Groups is not large. Typically we find $80 \%$ of the Sick Group and $20 \%$ of the Control Group above the median of the pooled distribution on any one stress stimulus trial. On UCS Trial 6 all but one of the Sick subjects and only two of the Controls are above the median of the pooled distributions. The pooled Sick and Well distributions typically find $70 \%$ of the Sick Group and $30 \%$ of the Well Group above the median.

\section{DISCUSSION}

The outstanding findings in the comparison of the Sick, Well and Control Groups implicate hyperlabile and hypersensitive autonomic functioning, early maternal loss, and disturbed associative hehavior as precursors of a variety of psychiatric breakdowns.

The findings of this study relating to autonomic hyperfunctioning are in agreement with certain recent work with both acute and chronic schizophrenics. Zahn (1964) has reported hyperresponsiveness, lower basal skin resistance and a failure of habituation of the GSR for 
schizophrenic subjects in selected parts of a relatively nonstressful situation. Other recent and methodologically sophisticated studies, in which schizophrenics have been subjected to stress have produced evidence of extremely high autonomic responsiveness in even the chronic schizophrenic (Ax et al., 1962; Malmo et al., 1951; and Ray, 1963). A review by Venables (1966) of recent research in this area seems to place the general form of the hyperresponsiveness hypothesis on a rather firm empirical footing.

When the senior author first advanced the hypothesis of autonomic hyperresponsiveness, as one of several hypothesized etiological precursors of schizophrenia (Mednick, 1958) there were only a few supportive studies that could be cited. "The majority of these studies reported lowered autonomic responsiveness in chronic schizophrenics" (Zahn, 1964, p. 167). The sense of the more recent empirical work on the schizophrenic, and the results of the present study bolster this hypothesis which is central to the theoretical orientation of this project. Two additional preschizophrenic characteristics, which were first hypothesized in 1958, were cxcessive generalization of autonomic responses and excessively slower recovery from stress. The first of these, generalization responsiveness, has found support in the present study. Both the $\mathrm{H}$ and Sick Groups evidenced elevated generalization gradients. However, the same cannot be said for the hypothesis of slow recovery. Both $\mathrm{H}$ and Sick Groups unequivocally showed abnormally fast rates of recovery from autonomic imbalance. It seems clear that this hypothesis of slow recovery merits abandonment. It may be of interest to try to reshape the theory to see what role quick autonomic recovery could play in the development of schizophrenia.

The theory identifies schizophrenia as a learned disorder of thought and suggests that there are certain physiological and environmental factors that predispose individuals to such learning.

The thought disorder consists of a set of conditioned avoidance responses which help the schizophrenic to control his autonomic hyperresponsivity. The avoidant responses (associations or thoughts) are learned on those occasions when the preschizophrenic escapes from some arousal-producing stimulus by switching to a thought which interrupts this arousal stimulus. The intruding association may then enable the individual to avoid (perhaps for just a moment) the arousal stimulus. This will automatically result in a momentary reduction in arousal level. (Such a reduction in arousal has been shown to have great reinforcement value.) This reduction in arousal level will reinforce the association between the arousal stimulus and the avoidant thought. This, in turn, will increase the probability of an avoidant associate response to future arousal stimulation. Each time this "arousalavoidant thought" pairing occurs, it will be automatically reinforced by a reduction in arousal and will increase in probability. Notice that the "avoidant thought-reinforcement" relationship is completely internal to the subject. It is a truly autistic process requiring no physical or social interaction for successful operation. After many such learning trials the individual will have built up a single avoidance response or a small repertoire of responses which will have the ability to remove him from arousal stimulation or at least modulate his arousal stimulation.

This repertoire of avoidant responses will be automatically cued whenever the individual senses a stressful stimulus. Perhaps we are observing the beginnings of this process in our Continual Association Test results. This automatic avoidance response will seriously 
interfere with sustained thought processes and long term sets. It is at the point when these conditioned avoidant responses begin to dominate the individual's thinking that he may be classified as schizophrenic.

According to the earlier version of the theory the preschizophrenic is especially prone to learning this avoidant pattern because of his extreme hyperresponsivity, excessive generalization and slow recovery from autonomic imbalance. However, the hypothesis of slow recovery has always caused critics to point out that this would cause the preschizophrenic to be reinforced more slowly and meagerly for avoidance than even the normal. The finding of an abnormally fast rate of recovery has forced us to alter the theory. It is now our hypothesis that one of the determining features of the preschizophrenic is his abnormally fast recovery; because of this fast rate of recovery he is more easily, quickly and thoroughly reinforced for avoidance than the normal. This taken together with his tendency to chronic hyperarousal will, in a harsh environment, inexorably push him to learn conditioned avoidant thought mechanisms. The revised theory then implicates rapid autonomic recovery from states of autonomic imbalance as a key factor in a complex of factors predisposing individuals to schizophrenia.

As mentioned above the finding of a failure of habituation has been reported by Zahn (1964). At first glance this finding may be seen as antagonistic to the findings on quick recovery. However, the recovery finding refers to single instances of states of imbalance while failure of habituation refers to a tendency to continue to respond to stimuli over an entire experimental session as though they had never been experienced before. Failure of habituation may prove to bc an independent factor. Before accepting this assertion, however, we shall explore the relationship between this variable and GSR latency, responsiveness and generalization.

\section{Maternal loss}

Early maternal loss through psychiatric hospitalization was a common precursor of breakdown in the Sick Group. This finding might be compared with research which has found a greater frequency of schizophrenics suffering early maternal loss by death (Hilgard and Newman, 1963). Both of these findings suggest an environmental-stress etiological contribution. However, in our sample we found that the mothers of the Sick Group not only were lost to the family earlier but were also more severely schizophrenic. In view of the findings reported here by Kety et al. (1968) we cannot disregard the possibility of a heavier genetic burden in the Sick Group as evidenced by the greater severity of their mother's illness. Two findings within the Sick Group reflect on this possibility. First, we found that within the Sick Group the very severely schizophrenic mothers were separated from their children when the children had a mean age of 3.75 years; the children of the moderately severe mothers were 8.80 years of age at separation $(t=2 \cdot 33,18 d f, p<0.025)$. The second finding concerns those members of the Sick Group who have been admitted to a psychiatric hospital or who are under psychiatric care. These subjects tend to be the more overtly ill members of the Sick Group with promiscuity and criminality as common symptoms. Eighty-eight per cent of these have very severely schizophrenic mothers; of those Sick Group subjects who have not been hospitalized, $50 \%$ have very severely schizophrenic mothers $\left(\chi^{2}=4.40,1 d f, p<0.05\right)$. What is suggested 
tentatively by these results is that the very severely ill schizophrenic mothers (who had less contact with their children) had children with symptom-rich, acutely disturbed, psychiatric involvement. The Sick subjects, who spent more time with their moderately severely schizophrenic mothers tend to be classed as severely schizoid, anhedonic, overconforming, and obsessive. They also tended strongly to manifest more severe associative Drifting $(t=2 \cdot 90$, $18 \mathrm{df}, p<0.005)$; these subjects also had significantly poorer Level of Adjustment scores $\left(\chi^{2}=4 \cdot 8,1 d f, p<0 \cdot 05\right)$. They also tended to be in a subgroup of individuals chosen as fast GSR responders, poor in habituation, high in generalization, fast in recovery and high amplitude responders $\left(\chi^{2}=11 \cdot 22,1 d f, p<0 \cdot 005\right)$. These results are highly congruent with those of Reisby (1967). He found that schizophrenics who had spent a relatively long time with their schizophrenic mother tended to develop a more process schizophrenic condition with slow, insidious onset. Schizophrenics having been separated earlier from their schizophrenic mother developed more acute, symptom-rich, reactive schizophrenia.

We present these results on the Sick-Well-Control comparisons with great tentativeness. While the groups are rather well matched and the Sick Group carefully selected, there is a total of only 60 cases. Our tentativeness is even greater regarding the comparisons relating to time spent with the schizophrenic mother. Here our $\mathrm{N}$ is only 20 . We hope to increase the interpretability of these results by selection of both "relatively sick" and "well" subgroups of the total L Group instead of just a single Control Group. We have one other safeguard built into the research design. As indicated above, we can expect approximately $50 \%(100$ subjects) of the $\mathrm{H}$ Group to develop some form of manifest psychiatric disturbance. This means that we have just observed the first wave of 20 disturbed subjects. We can expect four more waves of 20 subjects each. These waves offer opportunities for cross validation. As the number of cases mounts it will be possible to separate out diagnostic groups (such as schizophrenia) for differential data analysis.

\section{REFERENCES}

Albee, G. W., LANe, E. A. and Reuter, J. M. (1964) Childhood intelligence of future schizophrenics and neighborhood peers, J. Psychol. 58, 141.

Auble, D. (1953) Extended tables for the Mann-Whitney statistic, Bull. Inst. Educ. Res., Indiana University, 1 (2).

Ax, A. F., Beckett, P. G. S., Cohen, B. D., Frohman, C. E., Tourney, G. and Gottleb, J. S. (1962) Physiologic patterns in chronic schizophrenia, in Wortis, B. (Ed.), Recent Advances in Biological Psychiatry, Vol. IV, Plenum Press, New York.

Ax, A. and Zacharopolous, G. (1961) Psychophysiological data processing, in P. L. Frommer (Ed.), Fouth International Conference on Medical Electronics, Fourteenth Annual Conference on Electrical Techniques in Medicine and Biology, Washington, McGregor \& Werner, 1961.

Bowir, E. M., Shellhammer, 'T. A. and Dally, J. M. (1960) School characteristics of male adolescents who later became schizophrenic, Am. J. Orthopsychiat. 30, 712-29.

DIDFRICHSEN, B. (1967) Formelle Karakteristika ved Associations-forlobet hos en grtape born med hoj risiko for schizophreni, Kobenhavns Universitel.

Fremminci, K. H. (1951) The Expectation of Mental Infirmity in a Sample of the Danish Population, Papers on Eugenics, No. 7, London, the Eugenics Society.

GoldFArb, C. and Erlenmeyer-Kimling, L. (1961) Changing mating and fertility patterns in sehizophrenia, in F. J. Kallmann (Ed.), Expanding Goals of Genetics in Psychiotry.

Heston, L. L. (1966) Psychiatric disorders in foster home reared children of schizophrenic mothers, Brit. J. Psychiat. 112, 819-25.

Higgins, J. (1966) Effect of child rearing by schizophrenic mothers, J. Psychiat. Re's. 4, $153-67$. 
Hilgard, J. R. and Newman, M. A. (1963) Parental loss by death in childhood as an etiological factor among schizophrenic and alcoholic patients compared with a non-patient community sample, J. Nerv. Ment. Dis. 137, 14-28.

Kallmann, F. J. (1946) The genetic theory of schizophrenia, Am. J. Psychiat. 103, 309-22.

Kety, S. S., Rosenthal, D., Wender, P. H. and Schulsinger, F. (1968) The types and prevalence of mental illness in the biological and adoptive families of adopted schizophrenics. A preliminary report. These Proceedings, p. 345.

LAne, E. A. and Albee, G. W. Childhood intellectual development of adult schizophrenics, J. Abnorm. Social Psychol. 67, 186-9.

LANE, E. A. and AlBEe, G. W. (1964) Early childhood intellectual differences between schizophrenic adults and their siblings, J. Abnorm. Social Psychol. 68, 193-5.

Lansing, J. B. and Mueller, E. (1967) Geographic Mobility of Labor, Institute of Social Research, Ann Arbor.

Lewis, A. J. (1957) The offspring of parents both mentally ill, Acta Genet. 7, 309-22.

Malmo, R. B., Shagass, C. and Smith, A. A. (1951) Responsiveness in chronic schizophrenia, J. Personality $19,359-75$.

Mednick, S. A. (1958) A learning theory approach to research in schizophrenia, Psychol. Bull. 55, $316-27$.

Mednick, S. A. and Freedman, J. (1960) Stimulus generalization, Psychol. Bull. 57, 169-200.

Mednick, S. A. (1962) Schizophrenia: a learned thought disorder, in G. Nielsen (Ed.), Clinical Psychology, Proceedings of the XIV International Congress of Applied Psychology, Copenhagen, Munksgaard.

MEDNICK, S. A. and WILD, C. (1962) Reciprocal augmentation of generalization and anxiety, J. Exp. Psychol. 63, 621-6.

Mednick, S. A. and Schulsinger, F. (1965a) A longitudinal study of children with a high risk for schizophrenia: a preliminary report, in S. Vandenberg (Ed.), Methods and Goals in Human Behavior Genetics, New York, Academic Press, pp. 255-96.

Mednick, S. A. and Schulsinger, F. (1965b) Children of schizophrenic mothers, Bull. Inter. Assoc. Appl. Psychol. 14, 11-27.

Mednick, S. A. (1966) A longitudinal study of children with a high risk for schizophrenia, Ment. Hyg. 50, 522-35.

Mednick, S. A. and MCNeIL, T. F. (in press) Current methodology in research on the etiology of schizophrenia. Serious difficulties which suggest the use of the high-risk group method. Psychol. Bull.

RAY, T. S. (1963) Electrodermal indications of levels of psychological disturbance in chronic schizophrenia, Am. Psychol. 18, 393.

Reisby, N. (1967) Psychoses in children of schizophrenic mothers, Acta psychiat. scand. 43, 8-20.

Schulz, B. (1939) Empirische Untersuchungen über die beidseitigen Belastung mit endogenen Psychosen, Z. Neurol. Psychiat. 165, 97-108.

Schulz, B. (1940) Kinder schizophrener Elternpaare, Z. Neurol. Psychiat. 168, 332-81.

Svalastoga, K. (1959) Prestige, Class and Mobility, Copenhagen, Gyldendal.

US Bureau OF THE Census (1956) US Census of Population: 1950, Vol. IV, Special Reports, Part 4, Chapter B, Population Mobility-States and State Economic Areas. US Government Printing Office, Washington, DC.

Venables, P. (1966) Psychophysiological aspects of schizophrenia, Brit. J. Med. Psychol. 39, $289-97$.

ZAHN, T. P. (1964) Autonomic reactivity and behaviour in schizophrenia, Psychiat. Res. Rep. 19, 156-71. 